\title{
Projecting and Forecasting Winter Precipitation Extremes and Meteorological Drought in California Using the North Pacific High Sea Level Pressure Anomaly $\mathfrak{d}$
}

\author{
MARIZA COSTA-CABRAL \\ Northwest Hydraulic Consultants, Inc., Seattle, Washington \\ John S. Rath, William B. Mills, And Sujoy B. RoY \\ Research and Development Group, Tetra Tech, Inc., Lafayette, California \\ PETER D. BROMIRSKI \\ Scripps Institution of Oceanography, University of California, San Diego, La Jolla, California \\ CRISTINA MILESI \\ NASA Ames Research Center, Moffett Field, California
}

(Manuscript received 27 July 2015, in final form 5 April 2016)

\begin{abstract}
Large-scale climatic indices have been used as predictors of precipitation totals and extremes in many studies and are used operationally in weather forecasts to circumvent the difficulty in obtaining robust dynamical simulations of precipitation. The authors show that the sea level pressure North Pacific high (NPH) wintertime anomaly, a component of the Northern Oscillation index (NOI), provides a superior covariate of interannual precipitation variability in Northern California, including seasonal precipitation totals, drought, and extreme precipitation intensity, compared to traditional ENSO indices such as the Southern Oscillation index (SOI), the multivariate ENSO index (MEI), Niño-3.4, and others. Furthermore, the authors show that the NPH anomaly more closely reflects the influence of Pacific basin conditions over California in general, over groups of stations used to characterize statewide precipitation in the Sierra Nevada range, and over the southern San Francisco Bay region (NASA Ames Research Center). This paper uses the term prediction to refer to the estimation of precipitation (the predictand) from a climate covariate (the predictor), such as a climate index, or atmospheric moisture. In this sense, predictor and predictand are simultaneous in time. Statistical models employed show the effectiveness of the NPH winter anomaly as a predictor of total winter precipitation and daily precipitation extremes at the Moffett Field station. NPH projected by global climate models is also used in conjunction with atmospheric humidity [atmospheric specific humidity (HUS) at the $850-\mathrm{hPa}$ level] to obtain projections of mean and extreme precipitation. The authors show that future development of accurate forecasts of NPH anomalies issued several months in advance is important for forecasting total winter precipitation and is expected to directly benefit water resource management in California. Therefore, the authors suggest that investigating the lead-time predictability of NPH anomalies is an important direction for future research.
\end{abstract}

Supplemental information related to this paper is available at the Journals Online website: http://dx.doi.org/10.1175/JCLI-D-15-0525.s1.

Corresponding author address: Mariza Costa-Cabral, Northwest Hydraulic Consultants, Inc., 16300 Christensen Road, Suite 350, Seattle, WA 98188.

E-mail: mcabral@nhcweb.com

\section{Introduction}

Establishing a statistical association between local precipitation and large-scale climate patterns has potential value for several applications in water resources planning over different time scales, among which are 1) seasonal forecasts of total precipitation, which can provide support for planning reservoir operations for 
water supply and flood control, over time frames of months; 2) forecasting the risk of intense precipitation and wet antecedent conditions that may lead to flooding, over seasonal time scales; and 3) projecting future changes in local precipitation that are consistent with climate model projections of large-scale variability over decadal time scales. Global climate models simulate larger-scale climate variability better than regional and local-scale precipitation, which is a challenging variable because of its complexity, its being influenced by topography, and the high spatial and temporal resolution of its physical dynamics, none of which can be fully represented in these models. The same is true of the climate models used for seasonal forecasting and decadal predictions of precipitation (Meehl et al. 2014). To circumvent the difficulty in obtaining reliable dynamical simulations of precipitation, statistical models of precipitation have been used in conjunction with global climate models to produce precipitation projections (e.g., Zorita et al. 1995; Zorita and von Storch 1999; Cavazos 1999; Wang and Zhang 2008; Zhang et al. 2010; Kharin et al. 2007, 2013).

The El Niño-Southern Oscillation (ENSO) phenomenon has been identified as the major driver of climate variability arising from the coupled ocean-atmosphere system of the Pacific basin (Wallace and Gutzler 1981; Philander 1983, 1990). Several studies have examined the influence of ENSO on precipitation and temperature over North America (e.g., Ropelewski and Halpert 1986, 1996; Shabbar et al. 1997; Gershunov and Barnett 1998; Cayan et al. 1999; Gershunov and Cayan 2003; Schubert et al. 2008; Zhang et al. 2010) and worldwide (Ropelewski and Halpert 1987; Peel et al. 2002, and references therein). These studies have documented associations between the strength and phase of ENSO and precipitation frequency and intensity over different regions, particularly the southwestern United States.

Of great importance to the southwestern United States is ENSO's influence on the East Asian jet stream position. During El Niño episodes, the East Asian jet stream typically changes its position and direction, taking a more zonal path and crossing the southwestern United States. Associated with this jet stream position is a shift of the Aleutian low southward and eastward (Bjerknes 1966) and the positioning of the main cycloneformation region closer to the coast of California, leading storm tracks to enter the southwestern United States. Thus, California has an increased likelihood of storms, precipitation extremes, and precipitation totals under El Niño conditions (e.g., Chikamoto et al. 2015).

In most previous studies focused on western U.S. precipitation, the phase and strength of ENSO has been represented by the Southern Oscillation index (SOI), which is used as a covariate in statistical models for precipitation prediction, including precipitation extremes (e.g., Cayan et al. 1999; El Adlouni et al. 2007; Wang and Zhang 2008; Zhang et al. 2010; Shang et al. 2011). The SOI is defined as the normalized difference in atmospheric sea level pressure (SLP) at two locations: one near Tahiti and the other near Darwin, Australia. These locations are close to the centers of action of the southern branch of the Hadley-Walker circulation (Bjerknes 1966, 1969) and were chosen given their long climatological records. Hence, the SOI represents a simple and effective measure of the state of atmospheric circulation drivers of this southern branch. The warm phase of ENSO is associated with negative SOI values sustained over several months. Conversely, the cold phase of ENSO (La Niña) is indicated by sustained positive SOI values.

Roughly half the time, however, ENSO is in a neutral phase and SOI is near zero. Such neutral conditions are not an indication of average meteorology over California. The currently ongoing multiyear drought in California provides an example of an extreme meteorological drought occurring at a time when both ENSO and the Pacific decadal oscillation (PDO; Zhang et al. 1997; Mantua et al. 1997) are in near-neutral states. In this paper, we investigate whether climate variability indices other than the traditional ENSO indices and the PDO index (PDOI) represent favored covariates (or predictors) of precipitation over California. In this paper, we use the term prediction to refer to estimating precipitation (the predictand) from a climate covariate (the predictor), such as a climate index (e.g., the SOI), or atmospheric moisture. In this sense, predictor and predictand are simultaneous in time.

We show that, despite its widespread usage, the SOI is a weak predictor of precipitation over most of California, excepting Southern California. We show that SOI's lesser-known northern counterpart, the Northern Oscillation index (NOI; Schwing et al. 2002), exhibits higher correlation coefficients with total precipitation over California and the southwestern region of the United States. The NOI was specifically proposed as a new index to represent the impacts on the North Pacific of tropical and extratropical climate events on intraseasonal, interannual, and decadal scales (Schwing et al. 2002). The NOI is defined as the anomaly in the difference in atmospheric sea level pressure at the North Pacific high (NPH) long-term mean (climatological) location $\left(35^{\circ} \mathrm{N}, 130^{\circ} \mathrm{W}\right)$ and a location near Darwin $\left(10^{\circ} \mathrm{S}, 130^{\circ} \mathrm{E}\right)$. These two locations are the centers of action of the northern branch of the Hadley-Walker circulation.

The NOI and SOI are strongly correlated (Schwing et al. 2002). These two indices share a component in 
common (the Darwin sea level pressure anomaly), and Schwing et al. (2002, their Fig. 2a) showed that their remaining components (the sea level pressure anomalies at Tahiti and the NPH) are also significantly correlated. Importantly, the NOI reflects specifically the state of the northern branch of the Hadley-Walker circulation and its associated jet stream.

We show that the NOI's predictive power for California precipitation results primarily from its first component [i.e., the North Pacific high sea level pressure anomaly (NPH anomaly)] and that the NPH anomaly by itself is a better predictor than NOI for California precipitation.

The NCEP-NCAR reanalysis dataset (Kalnay et al. 1996) is used (in section 2) to investigate the correlation between the NPH anomaly and California precipitation over 1948-2014, including seasonal precipitation totals and the Palmer drought severity index (PDSI), using spatial data as well as point-based data (precipitation indices used in the main water supply region of the state, the upper-elevation watersheds of the Sierra Nevada that flow into the Central Valley).

Having established the predictive ability of the NPH anomaly for California precipitation, we then examine its predictive skill at the location of NASA Ames Research Center in the southern San Francisco Bay. This location was selected as part of a larger evaluation of climate impacts to NASA centers nationwide (Rosenzweig et al. 2014), and because it is representative of the highly urbanized, low-lying, and flood-prone lands surrounding the southern San Francisco Bay. We develop two statistical models (section 3), the first for predicting the likelihood of intense daily precipitation and the second for predicting winter season (December-March) precipitation totals, both using the NPH anomaly and the $850-\mathrm{hPa}$ atmospheric specific humidity (HUS) as covariates (or predictors). These models are then used to obtain projections based on GCM runs from the CMIP5 dataset. In the final section (section 4), we present the conclusions and a discussion of important practical applications of our findings. This work is focused on identifying and applying the relationships between precipitation and the NPH anomaly, not on the prediction of NPH itself.

\section{Datasets used in this work}

The daily rainfall datasets were downloaded from the National Centers for Environmental Information website (http://gis.ncdc.noaa.gov/) for stations Moffett Field, San Jose, and Palo Alto. Hourly rainfall datasets for Moffett Field and San Jose were also downloaded from the same website. The hourly data, and the daily data for San Jose and Palo Alto, were used for filling the gaps in the daily Moffett Field station time series, as described in detail in the supplemental material. The monthly SOI and NOI values were downloaded from the NOAA/ESRL Physical Sciences Division (PSD) website (http://www.esrl.noaa.gov/psd/data/climateindices/ list/). All precipitation index data for the Central Valley were downloaded from the California Data Exchange Center website (http://cdec.water.ca.gov/).

The monthly mean sea level pressure data from the NCEP-NCAR reanalysis dataset were downloaded from NOAA/ESRL PSD (http://www.esrl.noaa.gov/psd/data/ gridded/data.ncep.reanalysis.derived.surface.html, file name: slp.mon.mean.nc), as were the monthly mean precipitation data from the NCEP-NCAR reanalysis dataset (http://www.esrl.noaa.gov/psd/data/gridded/data. ncep.reanalysis.derived.surfaceflux.html, file name: pres. sfc.mon.mean). Reanalysis datasets, such as the ones used in this work, are based on simulations by dynamical climate models combined with observations and entail considerable uncertainty [characterized, e.g., in Bosilovich et al. (2008), Guirguis and Avissar (2008), and Janowiak et al. (1998)].

\section{The NPH anomaly versus traditional ENSO indices as a predictor of seasonal precipitation and extreme precipitation in California}

To investigate the relationship between high and low precipitation in California, the SLP composite anomalies are shown in Fig. 1 for the 11 highest (Fig. 1, top) and 11 lowest (Fig. 1, bottom) precipitation water years in California. During both regimes, the strongest SLP anomalies can be seen in the northeastern Pacific. The locations of the peak SLP anomalies are northwest of the climatological winter position of the North Pacific high (indicated on the maps). The composite anomalies at Darwin and Tahiti are comparatively small.

Associations between large-scale climate and local precipitation can be inferred from linear correlation of climate indices with precipitation. The spatial variability of linear correlation values between six monthly climate variability indices and precipitation across North America in December-March is shown in Fig. 2. For California and much of the U.S. southwest region, the $\mathrm{NPH}$ anomaly (Fig. 2a) achieves correlation values far higher than the ENSO or the PDO indices (Figs. 2c-f). The NOI, of which the NPH anomaly is a component, also correlates highly with precipitation over this region (Fig. 2b). Linear correlation values $|r|$ between monthly NPH anomaly and precipitation totals for DecemberMarch are above 0.5 over all of California, above 0.6 over most of California, and above 0.7 over San Francisco Bay and a long stretch of coast south of the bay (Fig. 2a). For the period January-March, correlation 

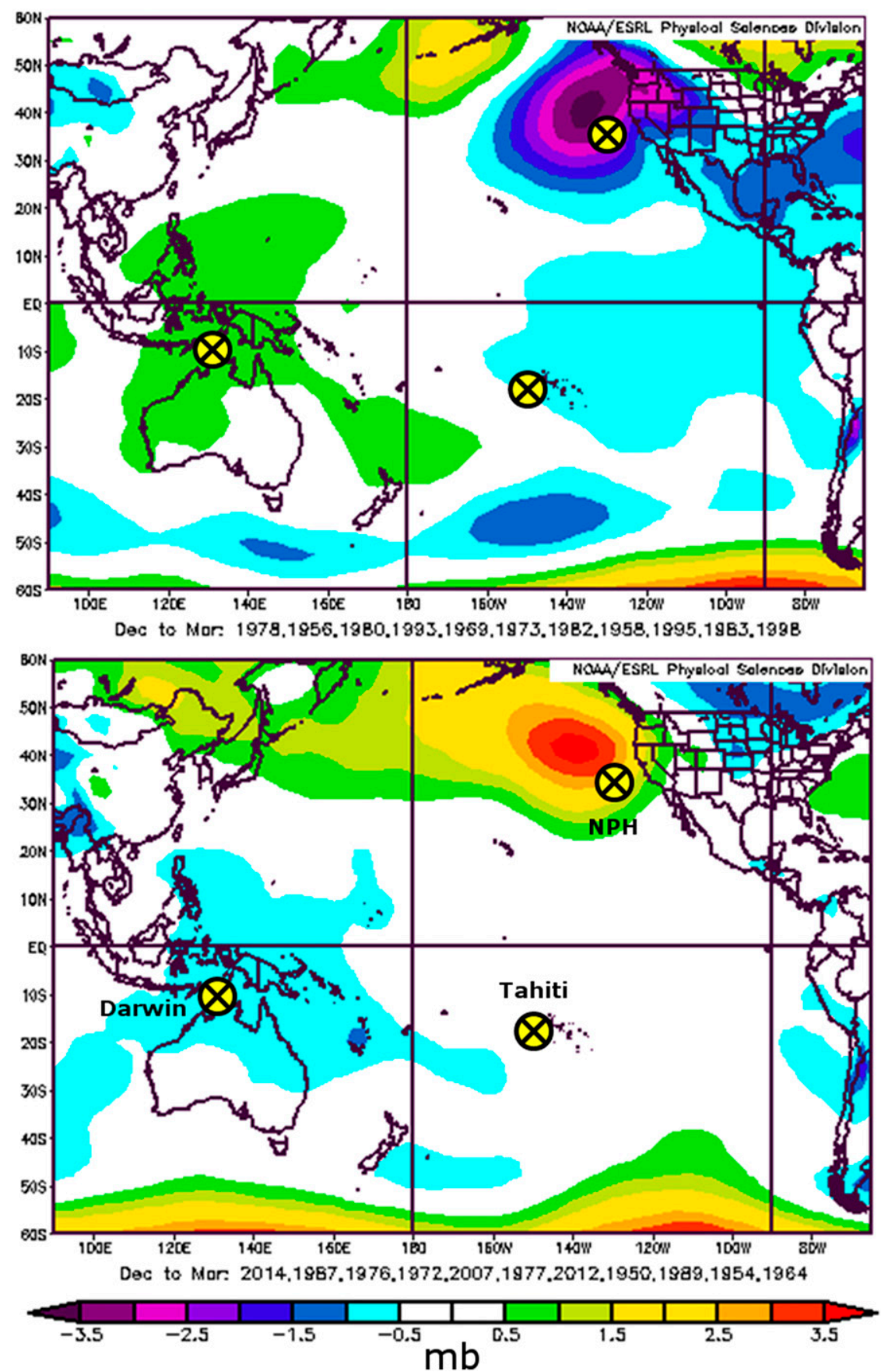

FIG. 1. Multiyear composite of sea level pressure anomalies ( $\mathrm{mb} ; 1 \mathrm{mb}=1 \mathrm{hPa})$ during winter (December-March) over the Pacific basin for (top) the San Francisco Bay area's 11 highestprecipitation water years and (bottom) 11 lowest precipitation water years, from the 66 water years of available reanalysis data (1949-2014). Water years are indicated at the bottom of each panel. The geographical reference locations used to determine the NOI and SOI are shown; they are the NPH climatological mean location $\left(35^{\circ} \mathrm{N}, 130^{\circ} \mathrm{W}\right)$, Darwin $\left(10^{\circ} \mathrm{S}, 130^{\circ} \mathrm{E}\right)$, and Tahiti $\left(18^{\circ} \mathrm{S}, 150^{\circ} \mathrm{W}\right)$. Note that the center of the dominant NPH anomaly region does not coincide with the center of the NPH. These figures were created using NOAA's web page (http://www.esrl.noaa.gov/psd/cgi-bin/data/composites/printpage.pl), which displays on demand variables from NCEP-NCAR reanalysis and the correlations between them. 
a) NPH

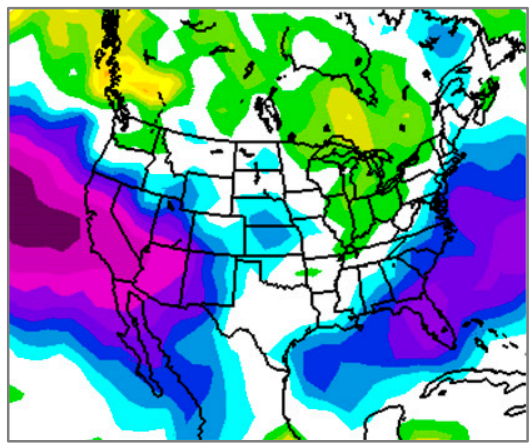

d) MEI

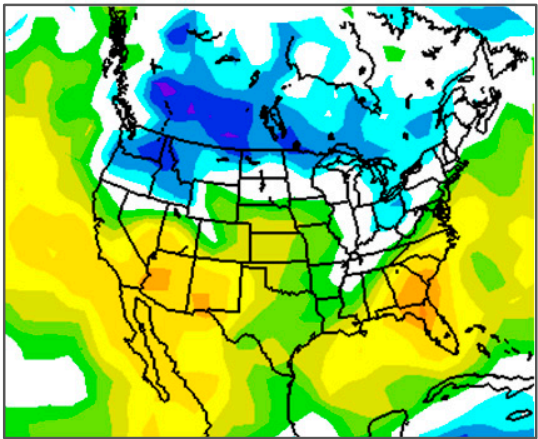

b) NOl

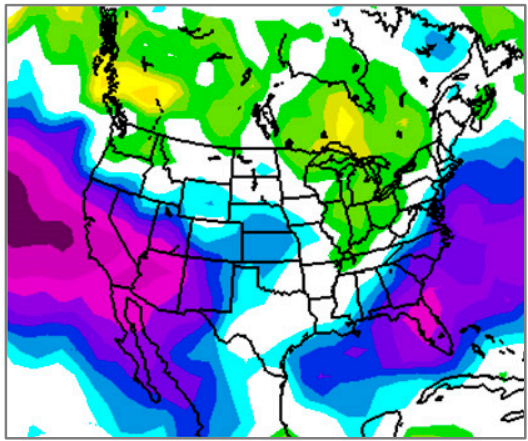

e) NIÑO 3.4 c) SOI

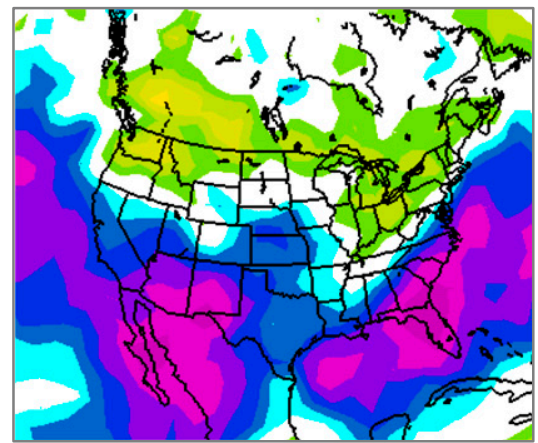

f) PDO
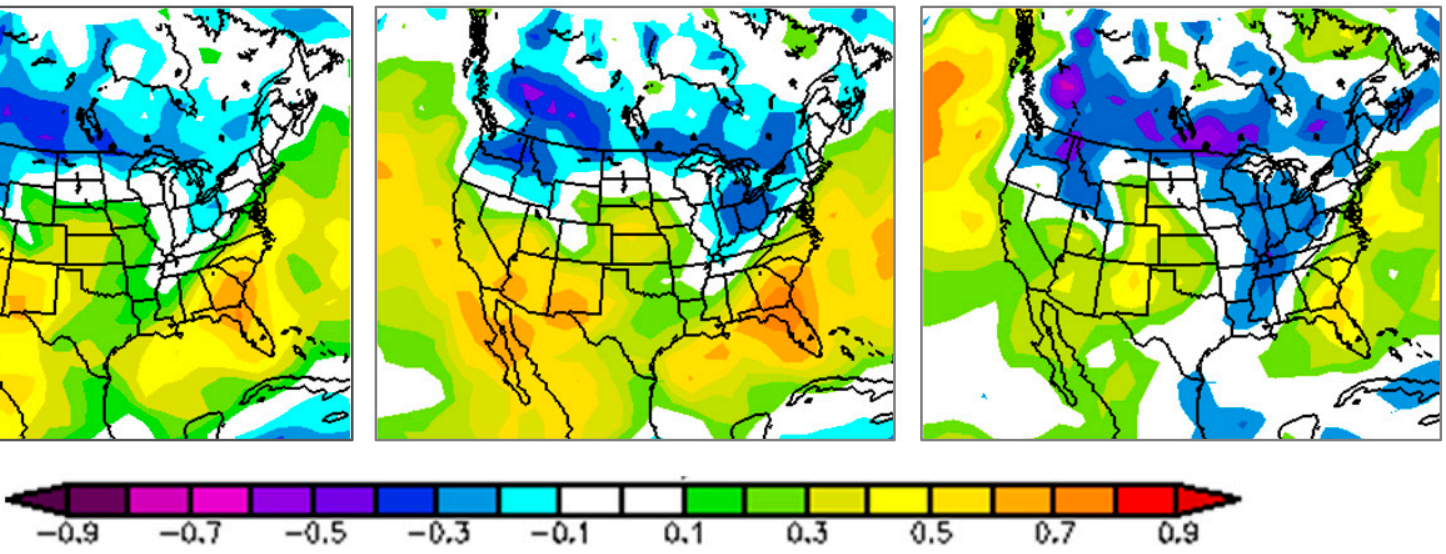

FIG. 2. Linear correlation coefficient $r$ between winter (December-March) monthly values of precipitation totals and the monthly values of six climate variability indices, in 1948-2014 (http://www.esrl.noaa.gov/psd/data/correlation/). NPH anomalies and NOI were determined from the NCEP-NCAR reanalysis monthly means dataset 1948-2014. The climate indices used in this figure are described in the text.

values are even higher and extend inland, surpassing 0.8 over much of California and surpassing 0.7 over all of California excepting its northernmost strip (see Fig. S.3 in the supplemental material).

Computed $|r|$ relating the SOI and December-March precipitation are not statistically significant for all California locations at latitudes higher than San Francisco and are near their minimum significance level for the San Francisco Bay area (Fig. 2c). The significance threshold value for a sample of $n=66$ water years and $p=0.05$ is $|r|=0.24$ for the case of an uncorrelated time series (obtained by inverting the classical Student's $t$ test for significance of Pearson correlation) and lower than that value if there is serial correlation [Fig. S.8 in the supplemental material shows test results accounting for serial correlation following Ebisuzaki (1997) and Wilks (2011)]. The values for $|r|$ are statistically significant over Southern California where they remain within a modest range, $0.4<|r|<0.5$, for the period of water years 1949 2014 (66 years; Fig. 2c). The predictive power of SOI for seasonal precipitation totals varies widely across North America (Fig. 2c) and across the globe (Fig. S.1c in the supplemental material).

Also shown in Fig. 2 is the linear correlation of precipitation with two ENSO indices, the multivariate ENSO index (MEI) and Niño-3.4 (Figs. 2d,e), as well as with the PDO index (Fig. 2f). Correlation values over California are weak in all three cases. The MEI (Wolter and Timlin 1998) is based on the six main observed variables over the tropical Pacific: SLP, surface wind (speed and direction), SST, surface air temperature, and cloud fraction. The Niño-3.4 is the sea surface temperature (SST) anomaly over the eastern tropical Pacific region encompassed within $5^{\circ} \mathrm{N}-5^{\circ} \mathrm{S}, 170^{\circ}-120^{\circ} \mathrm{W}$ (Cane et al. 1997; Kaplan et al. 1998). The PDO is defined as the leading principal component of monthly SST anomalies in the North Pacific Ocean northward of $20^{\circ} \mathrm{N}$ (Zhang et al. 1997; Mantua et al. 1997). Results for six additional climate variability indices provided by NOAA are included in Fig. S.1 of the supplemental material. 


\section{Correlation of PDSI and NPH}

a) Nov.-Mar.

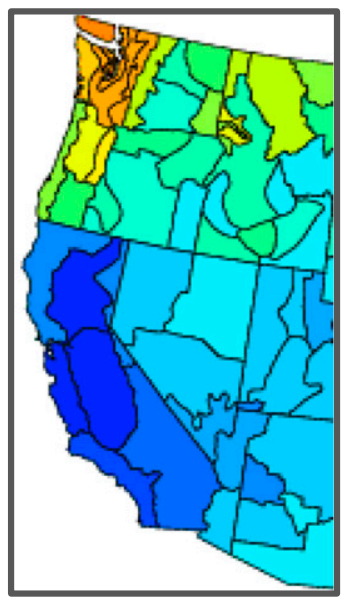

b) May-Sep.

(NPH leads by 5 months)

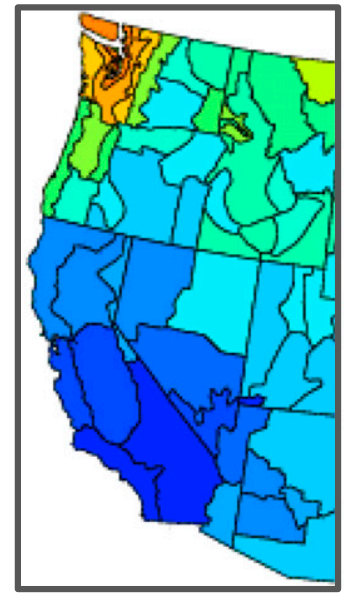

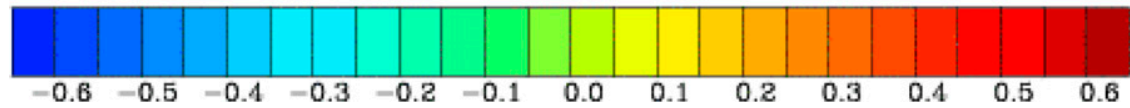

FIG. 3. Linear correlation coefficient $r$ between the monthly NPH anomalies and the monthly PDSI in (a) winter and (b) summer, for water years 1949-2012. For summer, a lag of 5 months (NPH leading) was used, to maximize correlation. The linear correlation between NovemberMarch NPH anomalies and May-September PDSI is shown in (b). This figure was produced with NOAA's interactive website (http://www.esrl.noaa.gov/psd/data/usclimdivs/correlation/), which provides the historical monthly PDSI values. More negative PDSI indicates more extreme drought conditions, resulting in the anticorrelation with positive NPH. NPH anomalies were obtained using the NCEP-NCAR reanalysis dataset.

As shown in Fig. 1 (bottom), the positive mode of $\mathrm{NPH}$ is associated with a strong high-anomaly SLP region over the northeastern Pacific. Abnormal northeastern Pacific high pressure ridges that extend from lower- to upper-atmospheric levels tend to block storm systems from reaching the California coast. Their role has been much discussed in the context of the currently ongoing multiyear drought in California, which has exhibited the strongest and most persistent ridge ever observed (e.g., Wang et al. 2014, 2015; Stevenson et al. 2015; Swain et al. 2014). The strong correlations shown in Fig. 2a, in conjunction with the pressure pattern shown in Fig. 1 (bottom), suggest that the association between the recent high NPH anomaly and California drought conditions is not unique to the ongoing drought but is a recurring phenomenon detectable using reanalysis data. Such surface pressure anomalies are frequently associated with atmospheric geopotential height anomalies over the northeastern Pacific, also shown to correlate with precipitation in California (Swain et al. 2014). The supposition that high NPH is associated with drought in
California is supported by the strong anticorrelation of the $\mathrm{NPH}$ anomaly with the PDSI, shown in Fig. 3, with correlation values in the range $0.5<|r|<0.7$ in both winter and summer.

Time series of cumulative departures of NPH from the monthly mean (i.e., running totals of the monthly anomalies) are shown in Figs. 4 and 5. Plotting cumulative departures from the mean is an effective way of visually evaluating the covariability between different variables, which may otherwise be obscured by significant year-to-year variability and by variation in the lag of the covariability. The precipitation's cumulative departure from the mean (Fig. 4, in black, expressed in meters) is obtained as the running sum of monthly anomalies from October 1948 to June 2014 for the NCEP-NCAR-reanalysis-derived precipitation dataset (approximately $1.9^{\circ}$ resolution) grid cell that covers much of California. Also shown is the NPH cumulative departure from the mean (Fig. 4, in blue, expressed in millibars), computed from the NCEP-NCAR-reanalysisderived sea level pressure dataset of $2.5^{\circ}$ resolution. 


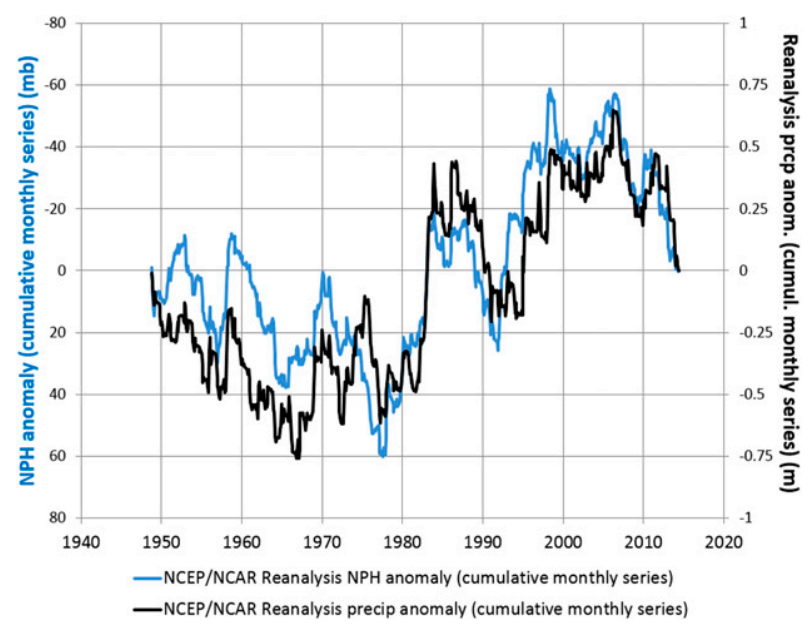

FIG. 4. Cumulative monthly anomalies from October 1948 to June 2014 (nearly 67 water years). Anomalies are computed by subtracting the monthly averages computed for this same period. The cumulative monthly anomaly of SLP at the NPH climatological location is shown in blue, referenced to the $y$ axis on the left (where values are in reverse order to aid comparison between the two curves). The cumulative NCEP-NCAR reanalysis gridded monthly precipitation anomalies are shown in black, referenced to the $y$ axis on the right, for the grid cell (approximately $1.9^{\circ}$ resolution) that covers much of California.

Strong covariability is observed between the two records when integrated in this manner over time, a type of relationship known as cointegration (Engle and Granger 1987). While there is significant uncertainty associated with spatial precipitation estimates from reanalysis datasets, and with any spatial precipitation datasets, the results in Fig. 4 are consistent with those obtained for gauge-based precipitation, such as shown for the Moffett Field gauge in Fig. 5.

The observed regional covariability between NPH and precipitation shown in Fig. 4 suggests that similar relationships may occur on local spatial scales where critical infrastructure can be affected. Focusing on the San Francisco Bay region, the daily precipitation record from the Moffett Field meteorological station over 1948-2014, located on the NASA Ames Research Center campus in the southern San Francisco Bay [station U.S. Air Force (USAF) Weather Bureau-Army-Navy (WBAN) identifier 74509023244 , located at $37.4^{\circ} \mathrm{N}, 122^{\circ} \mathrm{W}$ ], is examined next. The methodology used for filling Moffett Field precipitation data gaps during 1994-96, data homogeneity tests, and tests for trends, are summarized in the supplemental material.

The monthly values of the variables of interest are shown in Fig. 5, expressed as their cumulative departure from their mean value in the 67-yr period covered (1948-2014). For each of the variables, monthly means were computed for each of the 12 months of the year, by averaging the 67 observed values. The time series of monthly anomalies was obtained for each variable by subtracting the monthly means from the original monthly time series. The running total of the monthly anomalies was then calculated and represents the cumulative departure from the mean. The precipitation graph (black line) resembles that of the reanalysis gridcell precipitation in Fig. 4, despite the much different spatial scale and different range of values between the two.

The cumulative monthly values of SLP anomaly (green line) calculated from the NCEP-NCAR reanalysis data in the grid cell centered at $37.5^{\circ} \mathrm{N}, 122.5^{\circ} \mathrm{W}$ that encompasses Moffett Field is shown in Fig. 5a. Some covariability between SLP and precipitation is observed, as expected given that storms producing high precipitation are associated with atmospheric pressure lows. Local SLP appears to capture much of the year-to-year and decadeto-decade variability; however, SLP does not capture the upward multidecadal trend witnessed after the late 1970s when the dominant sign of the PDO switched from negative to positive. The cumulative value of the SOI (Fig. 5c) and NOI (Fig. 5d) captures some of the precipitation variability at different time scales; however, both severely fail to capture important time periods, such as the 1980s.

Much better covariability with precipitation is found for the cumulative NPH anomaly (also calculated from the NCEP-NCAR reanalysis dataset; Fig. 5b). NPH has its highest year-to-year variability in the month of January; hence, the January NPH anomalies dominate variability shown. The mean January values of NPH anomaly covary closely with the values of precipitation totals in each water year, as well as number of wet days and the annual maximum 5-day precipitation (shown in Fig. S.5 of the supplemental material).

Based on the above insights, we demonstrate the relationship between monthly values of NPH anomaly and wintertime precipitation at different combinations of gauges used to characterize the Central Valley of California's water supply (data obtained from the California Department of Water Resources; http://cdec. water.ca.gov/) and at the Moffett Field location described previously. Monthly relationships with the NPH anomaly are shown, and linear correlation values $r$ are given in Fig. 6 for the eight-station index for the northern Sierra Nevada (code 8SI), the five-station index for the San Joaquin basin (code 5SI), and the six-station index for the Tulare basin (code 6SI), for 1948-2015. These three groupings represent the major subbasins in the Central Valley, and these precipitation indices are used in developing water supply forecasts each water year for these river basins (part of the annually issued Department of Water Resources Bulletin 120). Because 


\section{a) SLP at Moffett Field}

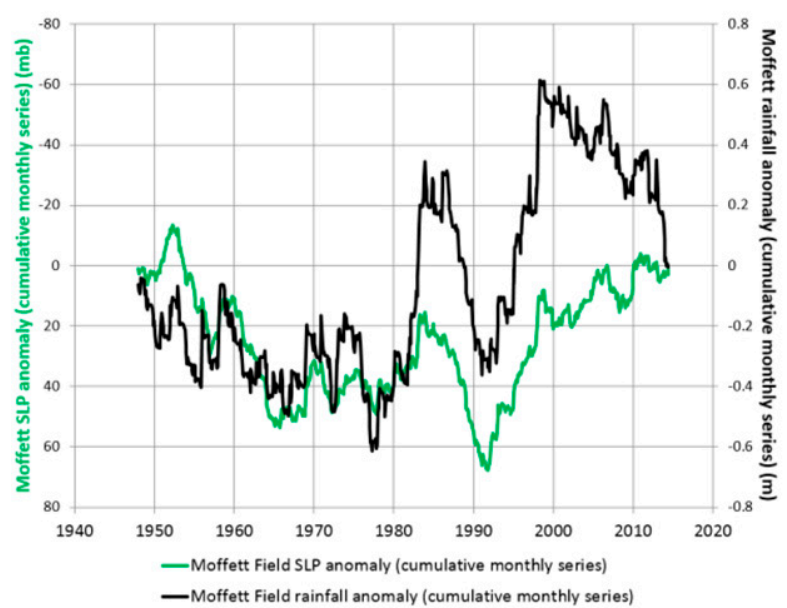

c) SOI

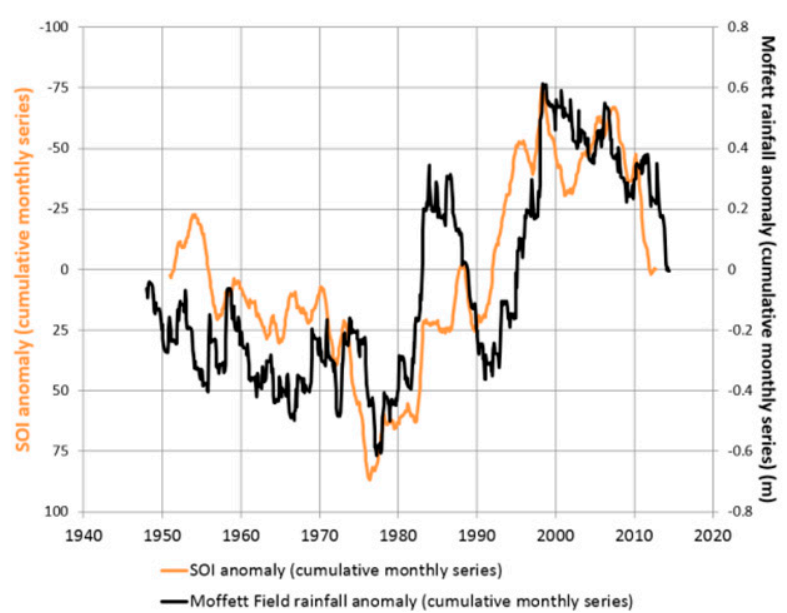

b) SLP at NPH location

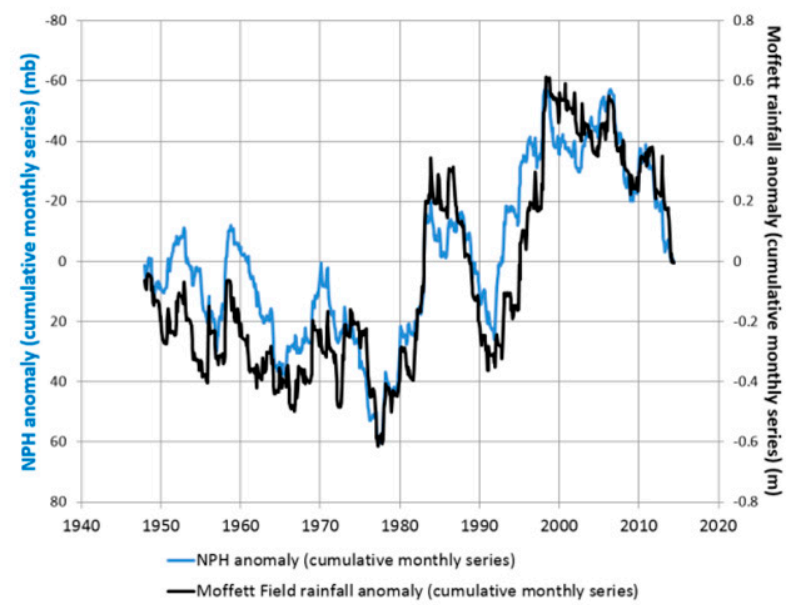

d) NOI

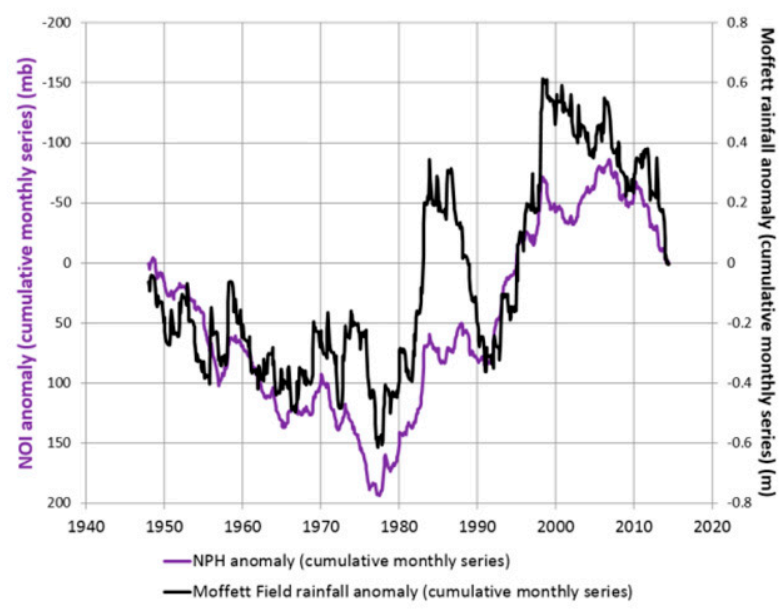

FIG. 5. Cumulative monthly anomalies from 1948 to 2014 (67 yr of data). Cumulative monthly precipitation anomalies measured at the Moffett Field meteorological station (black line) are shown in all panels (right $y$ axis). The left $y$ axis in all panels has values in reverse order, to aid comparison between curves. The colored curves represent the cumulative monthly anomalies of (a) SLP at the Moffett Field reanalysis grid cell (green curve), centered at $37.5^{\circ} \mathrm{N}, 122.5^{\circ} \mathrm{W}$, (b) SLP at the climatological mean winter location of the North Pacific high (blue curve), $35^{\circ} \mathrm{N}, 130^{\circ} \mathrm{W}$, (c) SOI (orange curve), and (d) NOI (purple curve).

much of California's precipitation by volume falls in these three basins, the water supply predictions developed for them have consequences for the entire state's water supply. The NPH is a strong predictor of precipitation at all of the station groupings and the Moffett Field station, especially for the latter months of the wet season from January through March.

\section{Projections of precipitation seasonal totals and extremes for NASA Ames Research Center}

In this section we develop statistical models to relate climatic indices (the predictors) to daily extreme and seasonal total precipitation at the NASA Ames Research Center (the predictands), with the goal of application to current conditions as well as future scenarios projected by global climate models. Our model of extreme precipitation is similar in principle to Zhang et al. (2010), but, in light of our findings in section 2, we use the NPH anomaly in lieu of the climate indices SOI, PDOI, and North Atlantic Oscillation index (NAOI) as the covariate (or predictor) of extreme precipitation. Similar to Zhang et al. (2010), Wang and Zhang (2008), and others, we also use HUS at the $850-\mathrm{hPa}$ level as a predictor. The inclusion of HUS is essential, given that projected atmospheric warming will result in higher 


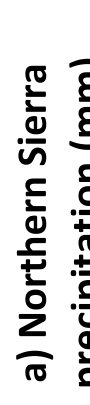

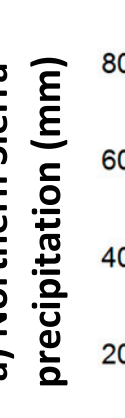
$800-$
$600-$
$400-$
$200-$
$0-$
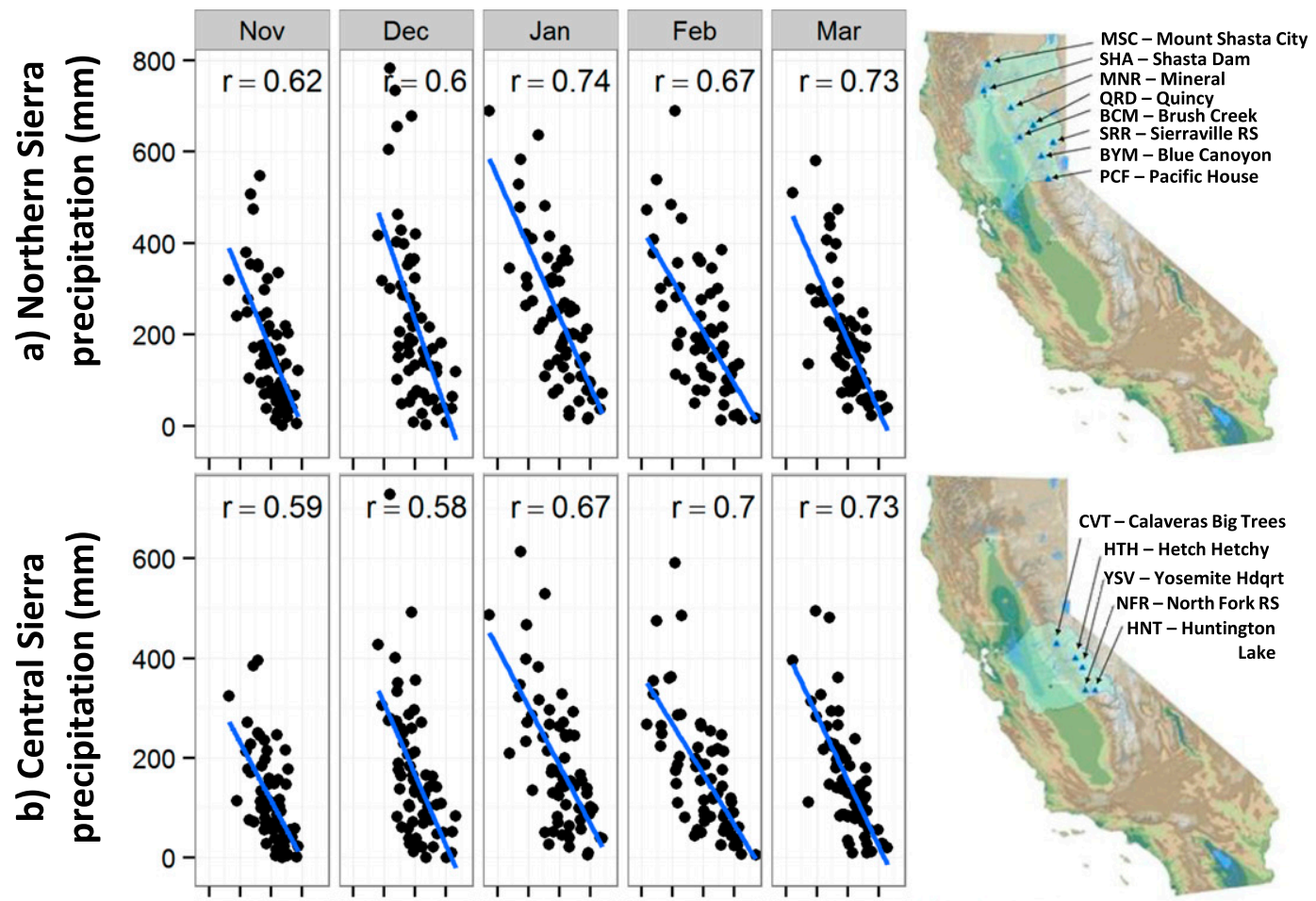

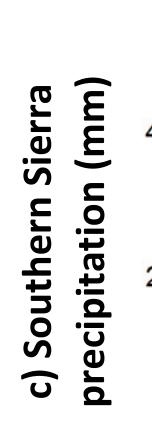
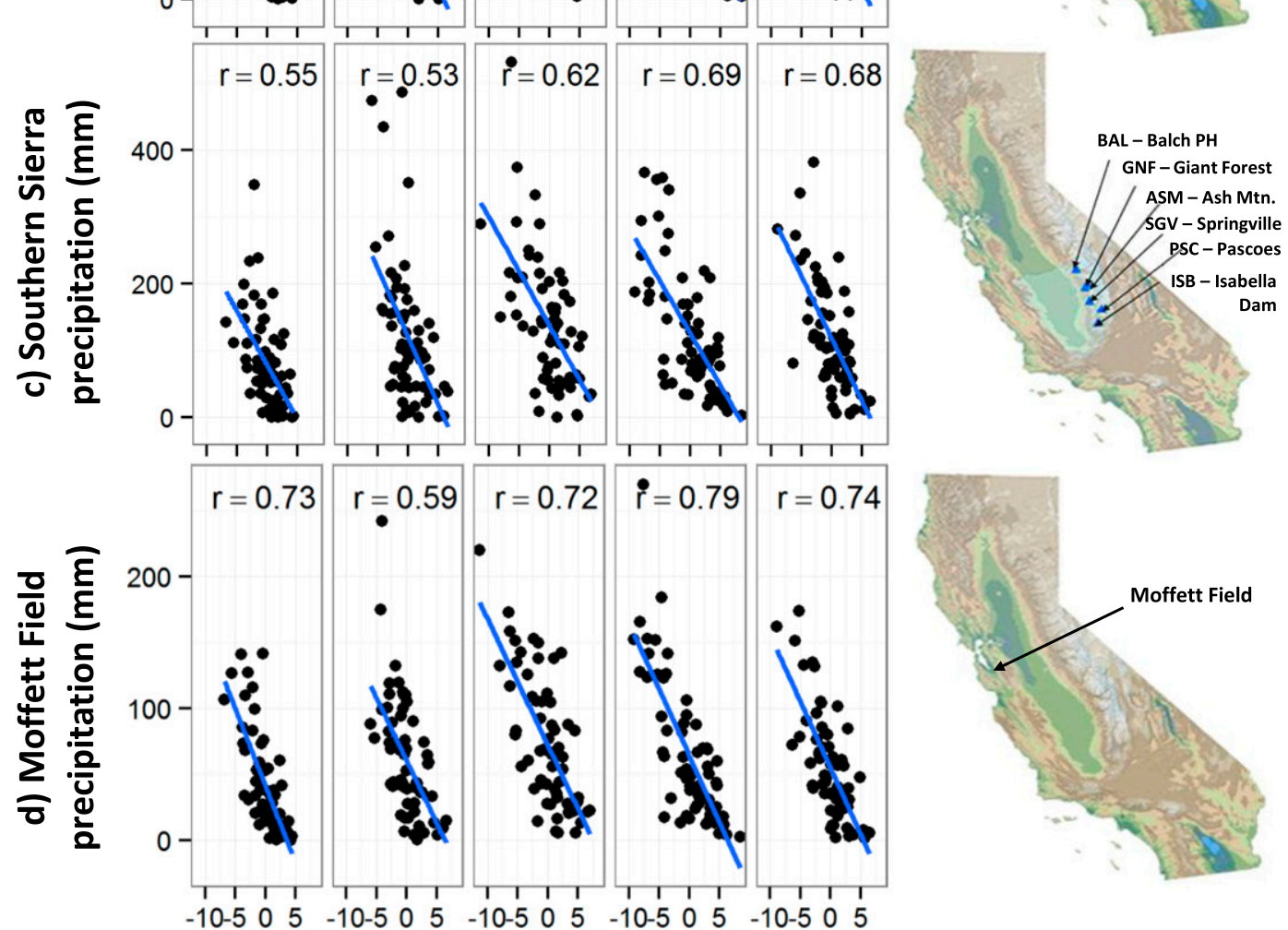

FIG. 6. Correlations between NPH anomalies (November-March) from the NCEP-NCAR reanalysis dataset and precipitation at different groups of stations in the Central Valley of California: (a) northern Sierra Nevada eightstation index, code 8SI; (b) San Joaquin basin (central Sierra Nevada) five-station index, code 5SI; (c) Tulare basin (southern Sierra Nevada) six-station index, code 6SI; and (d) Moffett Field station in the southern San Francisco Bay. [The data source for (a)-(c) is http://cdec.water.ca.gov/.] 
moisture content in air masses arriving in California from the Pacific Ocean with the potential for significant effects on precipitation extremes (Trenberth 1999). We also construct a model of total precipitation through the wet season using the same covariates at the seasonal level.

\section{a. Historical datasets for model training}

The historical daily precipitation data for the Moffett Field meteorological station at NASA Ames Research Center (station USAF WBAN identifier 745090 23244) span from March 1945 to mid-October 2012. Missing data were filled using recordings at nearby meteorological stations, as described in the supplemental material. The precipitation time series was successfully tested for homogeneity and trends over time, with no significant trends detected (see the supplemental material).

The statistical extreme value model was trained on standardized values of two predictors: 1) the monthly NPH anomaly and 2) monthly maxima of HUS at the 850-hPa level. The time series of both predictors were extracted from the NCEP-NCAR reanalysis dataset. The standardization consists of subtracting the long-term (climatological) mean from each monthly value and then dividing by the monthly standard deviation. This is helpful in interpreting the relative importance of each covariate in the model (e.g., Gelman and Hill 2007).

\section{b. Model of extreme precipitation intensity}

The monthly maxima of Moffett Field daily precipitation data (summarized in Fig. 7, showing November through March to be the period most prone to extremely high values of daily precipitation) are considered to be conditionally independent realizations of random variables with a generalized extreme value (GEV) distribution with parameters determined by a multilevel linear regression of the covariates-monthly $\mathrm{NPH}$ anomaly and monthly maximum value of daily average HUS. Only the extreme precipitation in the wet season (October-May) was modeled.

The model can be mathematically described as follows:

$$
\begin{aligned}
\mathbf{y} & \sim \operatorname{GEV}(\mu, \sigma, \xi) ; \\
\mu & =\mathbf{X} \beta_{\mu} ; \\
\log \sigma & =\mathbf{X} \beta_{\sigma} ; \\
\xi & =\beta_{\xi} ; \\
\boldsymbol{\beta} & =\left(\beta_{\mu}, \beta_{\sigma}, \beta_{\xi}\right) \sim N(\boldsymbol{\gamma}, \mathbf{\Sigma}) ;
\end{aligned}
$$

where $\mathbf{X}$ is the matrix of covariates (including an intercept); $\boldsymbol{\beta}$ is the vector of regression coefficients for the GEV location, scale, and shape parameters $-\mu, \sigma$, and $\xi$, respectively; $\boldsymbol{\gamma}$ and $\boldsymbol{\Sigma}$ are the parameters of the grouplevel model; $\mathbf{y}$ is the vector of Moffett Field monthly precipitation maxima; and $\operatorname{GEV}(\cdot)$ and $N(\cdot)$ are the densities of the GEV and multivariate normal distributions, respectively. The logarithm of the scale parameter $\sigma$ is used to ensure the parameter assumes only positive values.

\section{c. Model of wet season precipitation total}

The seasonal precipitation total for the wet season (October-May) was modeled using a robust linear model with 7 degrees of freedom, where the location parameter is defined to be a linear function of the climate covariates:

$$
\mathbf{y} \sim t_{7}(\mathbf{X} \boldsymbol{\beta}, \sigma) .
$$

Here, $t_{\nu}(\mu, \sigma)$ is the Student's $t$ density with 7 degrees of freedom, location parameter $\mu$, and scale parameter $\sigma$; $\mathbf{X}$ is the matrix of covariates; $\mathbf{y}$ is the vector of observations; and $\boldsymbol{\beta}$ is the vector of regression coefficients for parameter $\mu$.

\section{d. Model of extreme low Sierra Nevada winter precipitation totals}

The December-March totals of the three Sierra Nevada precipitation indices (Fig. 6) were fit to the GEV, gamma, and Pearson type-III distributions via maximum likelihood estimation. The gamma distribution had the smallest value of the Akaike information criterion (AIC; a goodness-of-fit statistic that penalizes models with additional parameters), and we therefore use the gamma distribution in a regression model including the NPH and HUS covariates:

$$
\begin{aligned}
\mathbf{y} & \sim \operatorname{Gamma}(k, \theta) ; \\
\log \mu & =\mathbf{X} \beta_{\mu} ; \\
\log \theta & =\mathbf{X} \beta_{\theta} ; \\
k & =\frac{\mu}{\theta} ;
\end{aligned}
$$

where $\mathbf{X}$ is the matrix of covariates; $\mathbf{y}$ is the vector of Sierra Nevada precipitation totals; $\mu, \theta$, and $k$ are the mean, scale, and shape parameters of the gamma distribution, respectively; and parameter-specific regression coefficients are denoted by $\beta$ with parameter subscripts.

\section{e. Parameter estimation}

All three models were estimated in a Bayesian context with relatively uninformative prior distributions. Posterior samples of the model parameters were simulated using a Markov chain Monte Carlo (MCMC) sampler implanted in the modeling language 


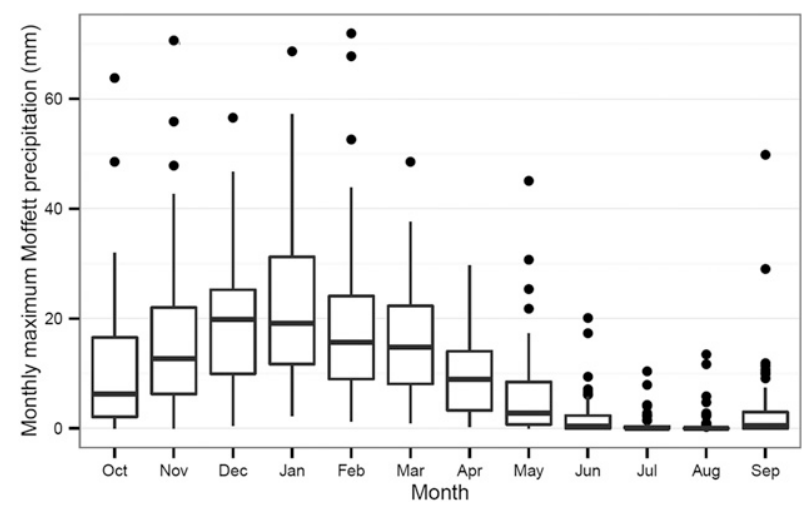

FIG. 7. Monthly box-and-whisker plot distributions and extremes (dots) of monthly maximum daily precipitation for the observed Moffett Field daily time series.

Stan. The sampler consisted of four independent chains of length 1000 (2000 for the seasonal models) with random starting points, and the first half of each chain was discarded to minimize initialization effects. The potential scale reduction factor-a diagnostic designed to monitor MCMC convergence (Gelman et al. 2013) — was below 1.02 for all quantities, which is near the asymptotic value of 1 . A quantile-quantile (Q-Q)-type diagnostic for assessing the performance of extreme value models (Coles 2001) - shown in Fig. S.59 of the supplemental material-displayed good agreement between the model and the data.

Parameter estimates for all three models (Table S.2 in supplemental material) indicated inverse relationships between precipitation and NPH anomaly and positive relationships with local HUS. In the model of total wet season precipitation, this is a straightforward result of the estimates of the regression coefficients. In the extreme value model, more negative values of the NPH anomaly and larger values of local HUS are associated with increases in the location and scale parameters of the GEV distribution, leading to increased likelihood of extreme precipitation. Estimates for the shape parameter are nearly uniformly positive, indicating that the heavy-tailed form of the GEV distribution fits the Moffett Field precipitation data best.

Posterior distributions of long-term return periods for precipitation (from the annualized model probability of exceedance of a specified daily rainfall amount) were obtained by averaging over parameter uncertainty captured by the posterior simulations and climate variability represented by the covariate values in the gamma and GEV models. Return levels are the precipitation values associated with specific return periods. Comparing the empirical return levels with the modeled values did not display any gross disagreements; see Fig. S.59 in the supplemental material.

\section{f. Selection of GCM runs}

Our selection of specific GCM runs from the CMIP5 dataset was guided by the preliminary work of T. Murdock et al. (2013, meeting presentation). T. Murdock et al. (2013, meeting presentation) aimed at identifying smaller sets of GCM runs, from the dozens of CMIP5 GCM runs, that 1) are representative of the range of climate projections of the complete set of runs and 2 ) include the most variability and the least redundancy. T. Murdock et al. (2013, meeting presentation) used a clustering algorithm that ordered the CMIP5 AOGCMs and (after excluding a few GCMs that performed least well in hindcasts) produced a rank list of which the first 12 captured nearly $90 \%$ of the variability of all projections for the North American west coast. More recently, their work was expanded globally over broad regions (Cannon 2015).

We selected the seven highest-ranked GCM runs on the list obtained by T. Murdock et al. (2013, meeting presentation) that provided the variables we need: CNRMCM5 run 1, CanESM2 run 1, ACCESS1.0 run 1, INMCM4.0 run 1, CSIRO Mk3.6.0 run 1, MIROC5 run 3, and MPI-ESM-LR run 3. (Expansions of acronyms are available online at http://www.ametsoc.org/PubsAcronymList.) Although CCSM4 run 2 ranked sixth on the list of T. Murdock et al. (2013, meeting presentation), we could not include it because its daily humidity values were not available. Subsequent research published by Polade et al. (2013) evaluated those AOGCMs that best reproduce the observed teleconnections with ENSO and PDO over the southwestern United States, indicating six preferred GCMs. Five of our original set of seven GCMs were included in the list by Polade et al (2013). Hence, our set of GCMs maximizes intermodel variability and simultaneously includes five of the highest-performing GCMs for representing the desired teleconnections. We chose representative concentration pathway 8.5 ( $\mathrm{RCP} 8.5)$ for our AOGCM runs, reflecting our subjective evaluation of this future pathway being more likely than the less intense pathways.

The projected daily values of the NPH anomaly were computed from the projected daily values of SLP, according to the definitions specified in the NOAA web page $^{1}$ and in Schwing et al. (2002), and summarized above in section 1. Daily projections of SLP and HUS at the $850-\mathrm{hPa}$ level were downloaded for RCP8.5 for the seven GCMs selected, from the CMIP5 data portal. ${ }^{2}$

\footnotetext{
${ }^{1}$ See http://www.pfeg.noaa.gov/products/PFEL/modeled/indices/ NOIx/compute.html.

${ }^{2}$ See http://pcmdi9.1lnl.gov.
} 


\section{g. Bias correction of the GCM-projected covariates}

The linear relationships between corresponding quantiles of historical scenario (1976-2005) and either midcentury (2040-69) or late-century (2070-99) GCM projections of the covariates were used to create GCMadjusted inputs for the statistical model. Box plot figures summarizing the projected changes in the covariates are provided in Fig. S.29 of the supplemental material.

There is generally a possibility that adjusting each covariate separately to account for projected climate change is inadequate; perhaps the relationship between the variables is projected to change, in addition to the values of the variables themselves. To account for this possibility, we compared the joint distribution of the (marginally) quantile-mapped historical data with that of the GCM scenario projections (see the supplemental material). The two joint distributions were sufficiently similar such that adjusting NPH anomaly and HUS separately was deemed to be adequate.

\section{h. Model results}

Using the two models of extreme precipitation (high daily rainfall at Moffett Field or low winter totals of Sierra Nevada precipitation) and the posterior samples of their parameters, we calculated the long-term daily precipitation return levels up to return periods of 100 years using the fitted GEV and gamma distribution functions. These calculations were repeated using several predictor datasets: one consisting of the reanalysis data used in fitting the model and one for each of the datasets adjusted according to the selected GCM projections. The term predictor is used here to refer to the inference of precipitation (the predictand) from a covariate (the predictor), even though predictor and predictand values are simultaneous in time. To get a sense of the relative importance of the two predictors in the precipitation projections, we generated two more return-level datasets leaving one of the predictors, NPH or HUS, fixed at the reanalysis values used in model fitting.

The posterior predictive distributions obtained for intense daily precipitation are displayed in Fig. 8, for the midcentury (2040-69) and late-century (2070-99) time horizons, on the top and bottom panels, respectively. To aid readability of a figure with multiple lines, we plot the relative exceedance probabilities-that is, the exceedance probabilities divided by the corresponding probability for reanalysis (historical) values. The seven GCM runs studied are color coded. The solid lines represent the posterior medians, while the dashed color-coded lines represent associated 25th and 75th percentiles. Figure 8 (left) shows the case where only the NPH anomaly was adjusted, while the HUS distribution was held equal to historical. In this case, the projected distributions do not deviate from the historical distribution (black line) for either the midcentury or late-century period. Figure 8 (center) shows the case where only HUS was adjusted, while the NPH anomaly distribution was held equal to historical. In this case, all GCMs project a rise in precipitation return levels, with a much larger departure from the historical distribution, especially for the late-century horizon. Figure 8 (right) shows the case where both covariates were adjusted. In this case, all GCMs project increased precipitation return levels, and the departures from historical are large. Two of the GCMs, CSIRO Mk3.6.0 and CanESM2, project posterior median increases in the exceedance probability of the current 100-yr (estimated to be $102 \mathrm{~mm} \mathrm{day}^{-1}$, the upper limit of the $x$ axis in Fig. 8) event by factors of about 3-4 for the midcentury period and 7-8 for the late-century period. These two GCMs project median increases in the 100 -yr event by about $50 \%$ for the mid-twenty-first-century period and above $70 \%$ for the late twenty-first-century period (shown in Fig. S.43 of the supplemental material).

Using the same combinations of time period (midcentury and late century) and leaving predictors fixed at their reanalysis values (adjust only NPH, adjust only HUS, and adjust both) that were used in the return-level calculations, we calculated the GCM predictions of seasonal total precipitation via Eq. (6). The distributions of these predictions are shown as box-and-whisker plots in Fig. 9. For the midcentury period, when only NPH is adjusted, the MIROC5 and MPI project slight decreases while CanESM2 and CSIRO Mk3.6.0 project increases; averaging the different GCMs into one distribution gives projections with little shift in either direction for midcentury and a slight upward trend for late century. For the late-century period, when only NPH is adjusted, more GCMs project increases, but they remain moderate in magnitude. In contrast, adjusting only HUS gives unanimous increases in precipitation for all GCMs, of considerable magnitude, especially for the late-century period. The HUS adjustment also results in precipitation distributions with large variability compared to the reanalysis distribution. Adjusting both variables gives projections of increased seasonal total precipitation and increased variability, primarily as a result of the HUS adjustment.

The return periods of up to 100 years for low values of winter Sierra Nevada precipitation totals according to the gamma regression model [Eqs. (7)-(10)] are shown in Fig. 10. The covariate datasets corresponding to each of the GCM runs are color coded with the solid lines representing the posterior median and the dashed lines representing the 25th and 75th percentiles. All GCMs project decreases in the probability of low Sierra Nevada 
Corresponding return period for reanalysis values of covariates (years)

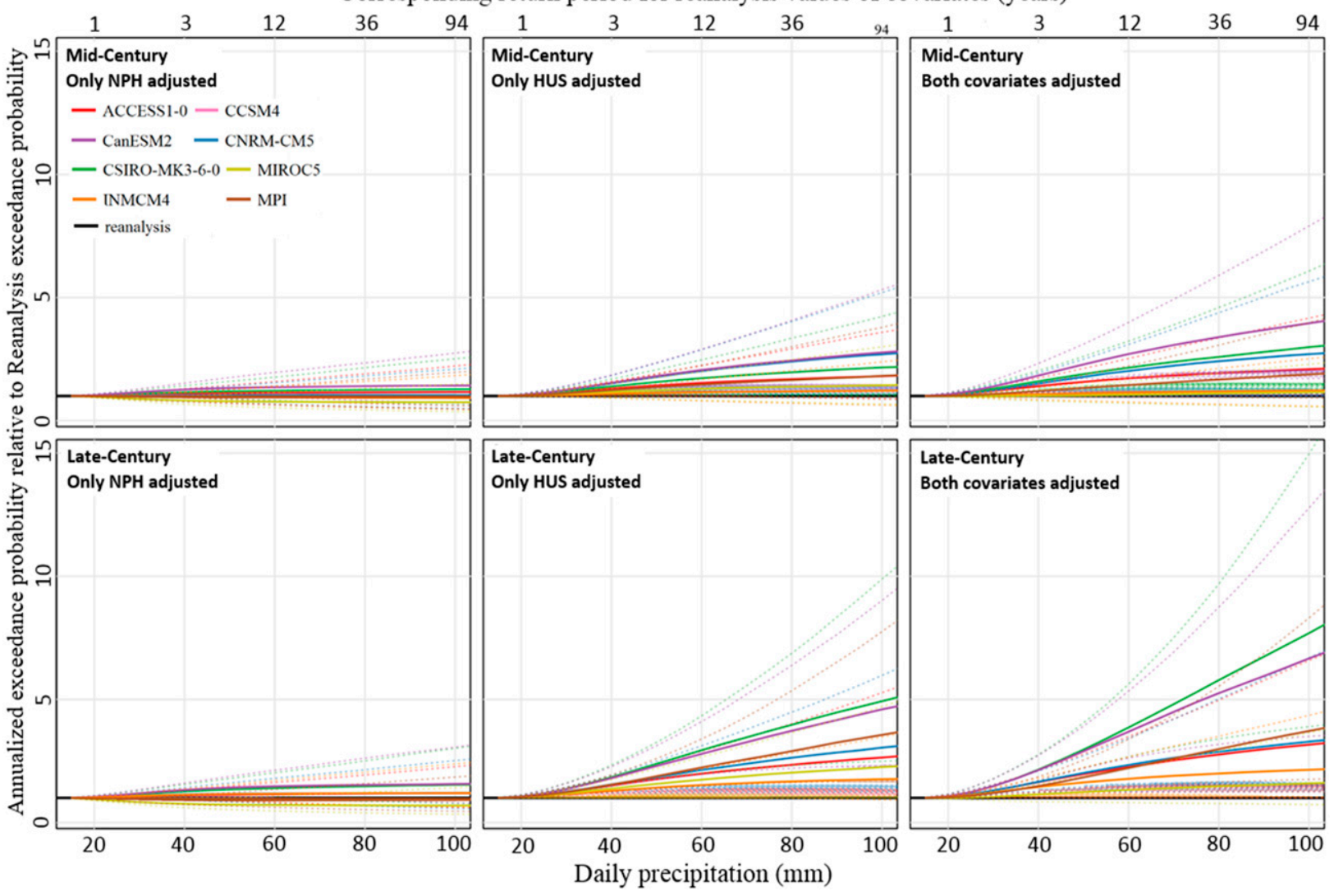

FIG. 8. GEV model exceedance probabilities for intense Moffett Field daily precipitation. Solid lines are posterior medians, and dotted lines span the pointwise 25 th and 75 th percentiles.

winter precipitation totals, a result that is driven mostly by their projected increases in the HUS covariate.

\section{Conclusions}

We have identified a simple climatic index that is more strongly associated with precipitation over California than the traditional climate indices used for forecasting precipitation. This index is the sea level pressure (SLP) anomaly at the climatological location of the North Pacific high $(\mathrm{NPH})$, which is approximately $35^{\circ} \mathrm{N}, 130^{\circ} \mathrm{W}$. The $\mathrm{NPH}$ is a component of the NOI, and the results are consistent with the basis of the NOI, proposed by Schwing et al. (2002) as a tool to relate the impacts of tropical and extratropical events along the eastern boundary of the North Pacific. Using the NCEP-NCAR reanalysis December-March average precipitation data for 19482014, we showed in section 2 that the NPH winter anomaly is strongly correlated with winter seasonal precipitation totals throughout California, including the Sierra Nevada slopes-a principal source of water to California's Central Valley agriculture and major California cities. The correlations were stronger than any of the traditional ENSO indices, such as MEI, SOI, and Niño-3, which are statistically significant only over Southern California. We also showed in section 2 that the NPH winter anomaly is strongly correlated with the Palmer drought severity index (PDSI) and with the annual 5-day maximum precipitation in the supplemental material.

Using the case study of NASA Ames Research Center in the southern San Francisco Bay, we developed two statistical models, one for precipitation extremes and the other for total winter precipitation, to be used for obtaining projected precipitation for future time horizons, based on GCM projections of NPH and atmospheric specific humidity (HUS) at the $850-\mathrm{hPa}$ level. We used the two statistical models in conjunction with CMIP5 projections of NPH and 850-hPa HUS for the Moffett Field case example. The first statistical model represents extreme daily precipitation in the form of a generalized extreme value (GEV) distribution whose parameters are functions of the two covariates, NPH and HUS. In this model, all GCM runs studied project increased precipitation values for fixed return periods, with large departures from historical values, explained 


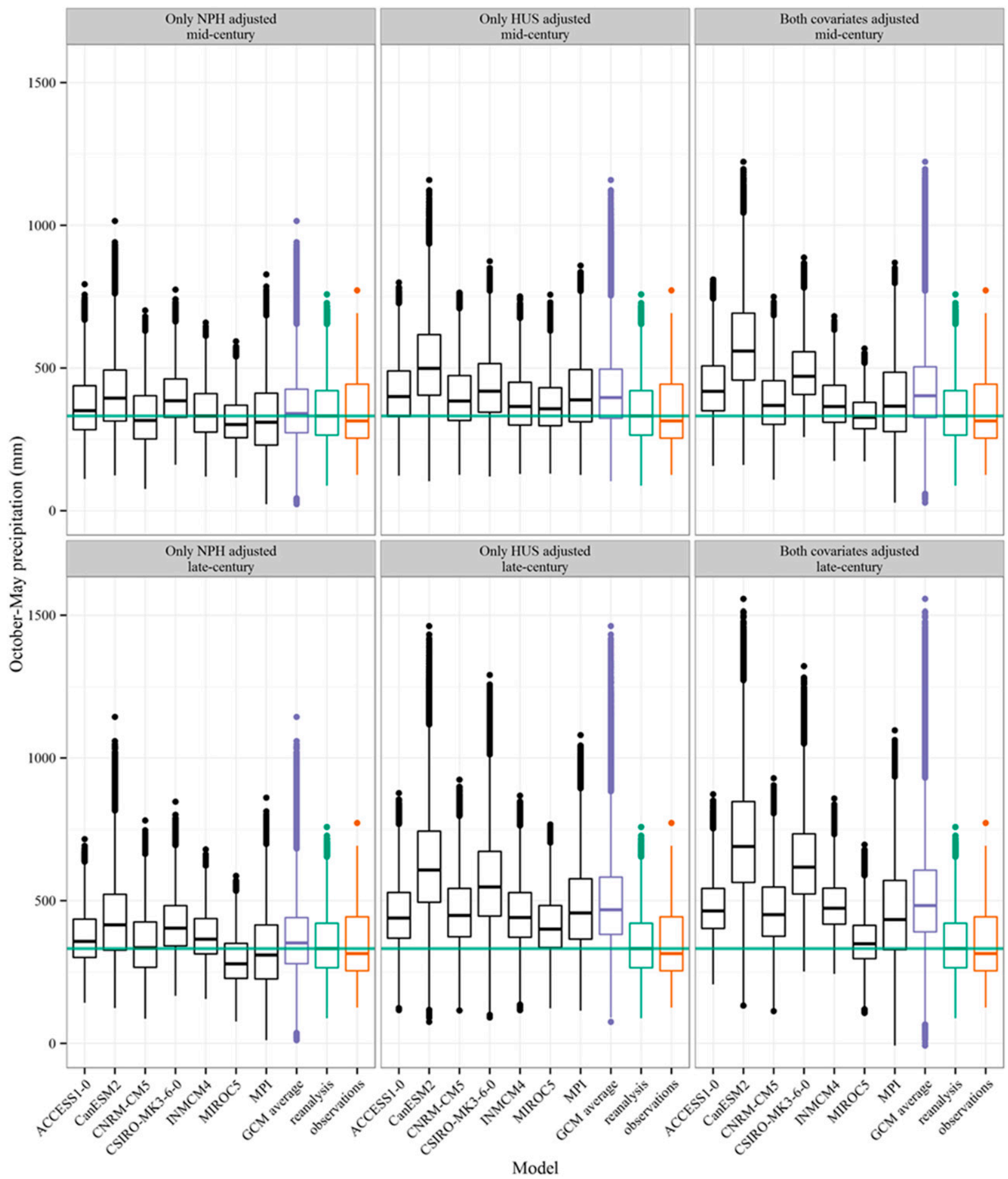

FIG. 9. Distributions of simulated and observed daily precipitation time series. The reanalysis (green) and observations (orange) box-and-whisker plots are repeated in each panel, for comparison to the model statistics. The reanalysis median is indicated by the horizontal green line.

principally by the projected increases in HUS. The second statistical model uses a robust linear model with 7 degrees of freedom to represent wet season precipitation totals, where the location parameter is a linear function of the two covariates, NPH and HUS. The HUS projections again dominate future changes in wet season precipitation, leading to increased average precipitation for all GCM runs, accompanied by increased variability. 


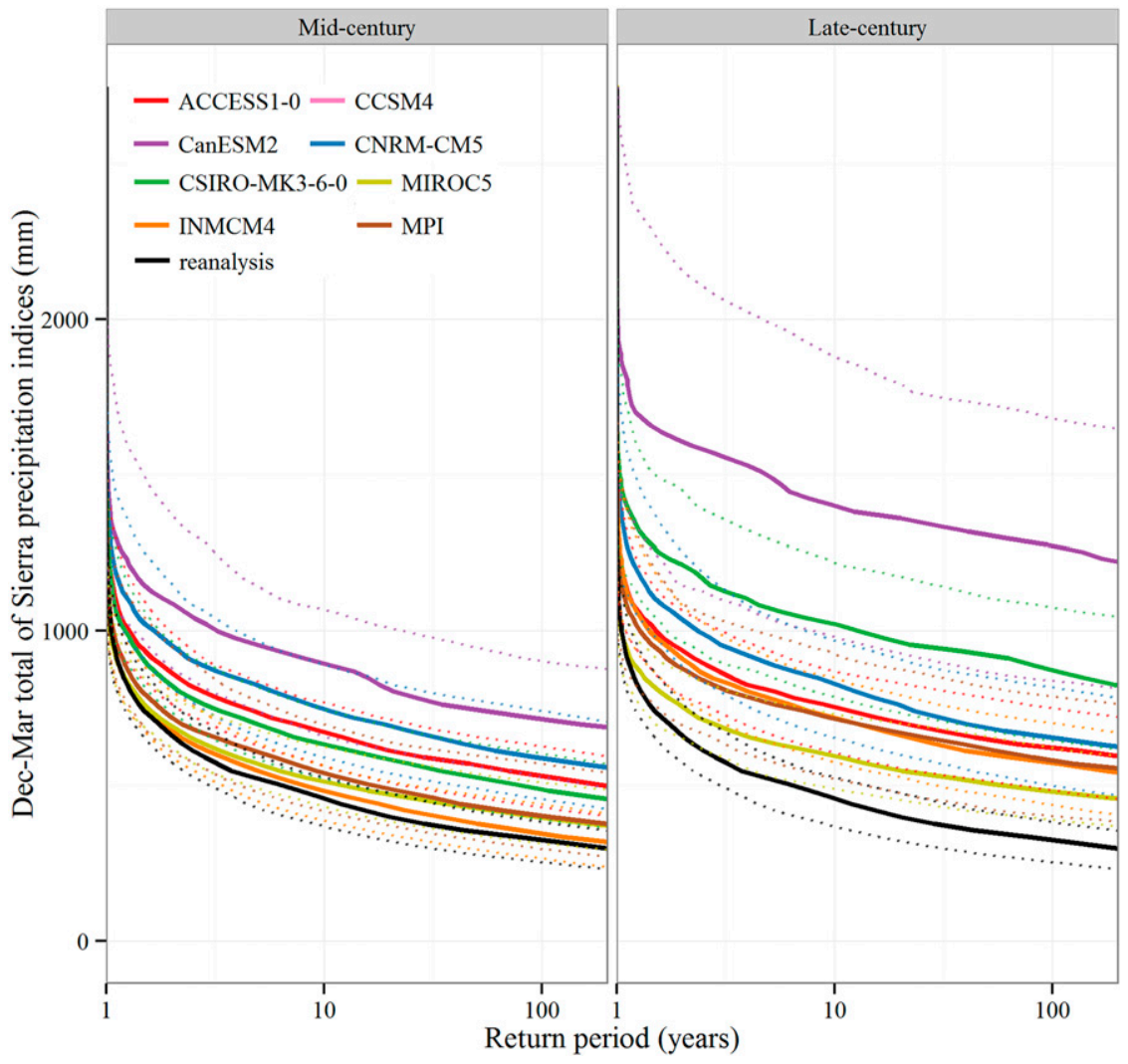

FIG. 10. Return periods of up to 100 years for low values of winter Sierra Nevada precipitation totals according to the gamma regression model [Eqs. (7)-(10)]. The covariate datasets corresponding to each of the GCM runs are color coded with the solid lines representing the posterior median and the dashed lines representing the 25th and 75th percentiles. All GCMs project decreases in the probability of low Sierra Nevada winter precipitation totals, a result that is driven mostly by their projected increases in the HUS covariate.

Future development may target similar statistical relationships at other locations using local data, particularly for estimates of extreme precipitation.

A third statistical model represents extremely low winter precipitation totals, in the form of a gamma distribution. We applied this model to the western Sierra Nevada precipitation indices and used the model to obtain projections of meteorologically dry years consistent with the GCM runs studied. We found a future tendency toward decrease in the probability of extremely low winter precipitation totals resulting mostly from the projected increase in HUS, with a small contribution from NPH changes. This result may be affected by the relatively small number of GCM runs used (although these were picked based on their ability to represent the CMIP5 models) and by possible nonstationarity of the empirically defined relationship between the NPH anomaly and California winter precipitation low extremes. We briefly compare this result with independent CMIP5-based studies that used different methodologies.
Berg and Hall (2015), examining 34 different GCMs run under RCP8.5 (as in our paper), found that for the midcentury period (2021-60) only 2 GCMs project increased frequency of extremely dry California winters (where dry is defined as below the 5th percentile) and that for the end-of-century period (2061-2100) only 10 GCMs do so. While ensemble means appear to indicate an increase in both extremely wet and extremely dry years, only 3 out of 34 GCMs actually yield both [see Table 2 of Berg and Hall (2015)]. Of the 19 GCMs that project increased frequency of extremely wet winters in 2061-2100, only 3 GCMs also project increased frequency of extremely dry winters. The key influence of atmosphere-ocean coupling on projected precipitation variability was studied by Yoon et al. (2015). Gao et al. (2015) showed that although a robust poleward shift of the subtropical jet in the North Pacific basin is expected, this will not significantly affect the dynamical effect on wintertime atmospheric rivers and suggested that this may be explained by the large intermodel uncertainties in the projections of 
wintertime circulation over the eastern North Pacific among the CMIP5 models.

While meteorological drought may tend to become less frequent, studies have shown that projected rising temperatures are expected to have a dominant effect in increasing the frequency and severity of hydrological and agricultural droughts in California (e.g., Cook et al. 2015), a tendency already identified in the historical record (Williams et al. 2015).

The major findings of this work can be summarized as follows. The monthly NPH anomaly is a strong explanatory variable for year-to-year precipitation variability in Northern California under current climatic conditions, including total water-year precipitation as well as risk of extremely intense precipitation. In this paper we use the term prediction to refer to estimating precipitation (the predictand) from a climate covariate (the predictor), such as a climate index, or atmospheric moisture. In this sense, predictor and predictand are simultaneous in time. When the NPH anomaly is used in conjunction with HUS at $850 \mathrm{hPa}$, statistical models can use these two predictors to obtain future projections of precipitation totals and risk of intense precipitation. Under current climatic conditions, HUS and NPH are sufficiently well correlated such that NPH alone is sufficient to use as a predictor for precipitation. Under future climatic conditions, the projected overall higher HUS levels require that both HUS $(850 \mathrm{hPa})$ and NPH be used as predictors for precipitation in statistical models. Future GCM-based projections indicate a dominant role for HUS over NPH in the changes projected for precipitation. All GCM projections studied indicate increased average and increased interannual variability of winter total precipitation. All GCM projections also indicated increased daily precipitation intensity for fixed return periods, with large departures from historical conditions. Two of the GCMs, CSIRO Mk3.6.0 and CanESM2, project median increases in the 100-yr daily precipitation event by about $50 \%$ for the mid-twenty-first-century period and above $70 \%$ for the late twenty-first-century period.

A principal finding of this work is that, if future research leads to accurate season-to-season forecasts of NPH monthly anomaly (whether obtained statistically or via dynamical models), they may be used to statistically derive forecasts of total winter precipitation. The NPH may have a better relationship with precipitation than the ENSO indices because, in addition to tropical forcing, it also receives influence from internal midlatitude variability. However, the question remains whether this internal midlatitude variability may or may not be forecastable.

Such a forecasting model would bring great benefit to planning activities related to precipitation and concerning drought and flooding risks. For example, many water supply reservoirs in California capture snowmelt in spring for supply later in summer. Under current operations, some reservoir storage is set aside for future floods over the course of the wet seasons-the flood control volume varying by month-and excess runoff is released downstream (e.g., Willis et al. 2011). A statistical tool relating NPH anomaly to precipitation indices, calibrated to specific locations corresponding to reservoir watersheds, may allow reservoir operators additional insight, on a year-to-year basis, on whether some of the flood storage could be utilized for water supply storage. This additional insight could be of great value in coming decades, where operators must make the most from a potentially more variable precipitation season, as well as declining snowpack and greater peaks in runoff in wet years (Hanak and Lund 2012; Fissekis 2008; Brekke et al. 2009). On this basis, we suggest that there may be a potential role for forecasts of NPH strength, such as that obtained by NOAA's National Weather Service Climate Forecast System, version 2 (CFSv2; Saha et al. 2014), for example, to anticipate both high- and lowprecipitation winters. Developing research into statistical forecasting of strong positive and negative NPH anomalies appears urgent and should include the investigation of the persistence of NPH anomalies over time and typical sequences of NPH evolution from season to season, the investigation of climatic precursors that may typically precede the development of extreme positive or negative NPH anomalies, and the investigation of any significant lagged correlations. This work demonstrates that advancements in forecasts of NPH are expected to have significant benefits for water resources, agriculture, energy, insurance, drought preparedness, and flood risk management in California.

Acknowledgments. Comments by Yoshimitsu Chikamoto, the journal's editor Mathew Barlow, and three anonymous reviewers have contributed to significant improvement of this manuscript and are gratefully acknowledged. This work was funded in part by the NASA ROSES program, under Grant NNX12AG33G, except for Cristina Milesi's work, which was funded by the NASA CASI program. The NASA ROSES grant was aimed at evaluating the impacts of climate change on NASA Ames Research Center's operations and facilities, and this manuscript reports on the portion of the grant dedicated to precipitation projections. Additional funding was provided by the Bay Area Environmental Research Institute, Northwest Hydraulic Consultants, Inc., and Tetra Tech, Inc. Additional support for Peter D. Bromirski under California Department of Parks and Recreation, Division of Boating and Waterways contract c157002 with SIO is gratefully acknowledged. 


\section{REFERENCES}

Battisti, D. S., and R. L. Naylor, 2009: Historical warnings of future food insecurity with unprecedented seasonal heat. Science, 323, 240-244, doi:10.1126/science.1164363.

Berg, N., and A. Hall, 2015: Increased interannual precipitation extremes over California under climate change. J. Climate, 28, 6324-6334, doi:10.1175/JCLI-D-14-00624.1.

Bjerknes, J., 1966: A possible response of the atmospheric Hadley circulation to equatorial anomalies of ocean temperature. Tellus, 18A, 820-829, doi:10.1111/j.2153-3490.1966.tb00303.x.

—_, 1969: Atmospheric teleconnections from the equatorial Pacific. Mon. Wea. Rev., 97, 163-172, doi:10.1175/ 1520-0493(1969)097<0163:ATFTEP > 2.3.CO;2.

Bosilovich, M., J. Chen, F. R. Robertson, and R. F. Adler, 2008: Evaluation of global precipitation in reanalyses. J. Appl. Meteor. Climatol., 47, 2279-2299, doi:10.1175/2008JAMC1921.1.

Brekke, L. D., E. P. Maurer, J. D. Anderson, M. D. Dettinger, E. S Townsley, A. Harrison, and T. Pruitt, 2009: Assessing reservoir operations risk under climate change. Water Resour. Res., 45, W04411, doi:10.1029/2008WR006941.

Cane, M. A., A. C. Clement, A. Kaplan, Y. Kushnir, R. Murtugudde, D. Pozdnyakov, R. Seager, and S. E. Zebiak, 1997: Twentieth-century sea surface temperature trends. Science, 275, 957-960, doi:10.1126/science.275.5302.957.

Cannon, A., 2015: Selecting GCM scenarios that span the range of changes in a multimodel ensemble: Application to CMIP5 climate extremes indices. J. Climate, 28, 1260-1267, doi:10.1175/ JCLI-D-14-00636.1.

Cavazos, T., 1999: Large-scale circulation anomalies conducive to extreme precipitation events and derivation of daily rainfall in northeastern Mexico and southeastern Texas. J. Climate, 12, 1506-1523, doi:10.1175/1520-0442(1999)012<1506: LSCACT $>2.0 . \mathrm{CO} ; 2$.

Cayan, D. R., K. T. Redmond, and L. G. Riddle, 1999: ENSO and hydrological extremes in the western United States. J. Climate, 12, 2881-2893, doi:10.1175/1520-0442(1999)012<2881: EAHEIT $>2.0 . \mathrm{CO} ; 2$.

Chikamoto, Y., and Coauthors, 2015: Skilful multi-year predictions of tropical trans-basin climate variability. Nat. Commun., 6 , 6869, doi:10.1038/ncomms7869.

Coles, S., 2001: An Introduction to Statistical Modeling of Extremes. Springer, $208 \mathrm{pp}$.

Cook, B. I., T. R. Ault, and J. E. Smerdon, 2015: Unprecedented 21st century drought risk in the American Southwest and Central Plains. Sci. Adv., 1, e1400082, doi:10.1126/ sciadv.1400082.

Ebisuzaki, W., 1997: A method to estimate the statistical significance of a correlation when the data are serially correlated. J. Climate, 10, 2147-2153, doi:10.1175/1520-0442(1997)010<2147: AMTETS $>2.0 . \mathrm{CO} ; 2$.

El Adlouni, S., T. B. M. J. Ouarda, X. Zhang, R. Roy, and B. Bobée, 2007: Generalized maximum likelihood estimators for the nonstationary generalized extreme value model. Water Resour. Res., 43, W03410, doi:10.1029/2005WR004545.

Engle, R. F., and C. W. J. Granger, 1987: Co-integration and error correction: Representation, estimation and testing. Econometrica, 55, 251-276, doi:10.2307/1913236.

Fissekis, A., 2008: Climate change effects on the Sacramento basin's flood control projects. M.S. thesis, Dept. of Civil and Environmental Engineering, University of California, Davis, $150 \mathrm{pp}$.

Gao, Y., J. Lu, L. R. Leung, Q. Yang, S. Hagos, and Y. Qian, 2015: Dynamical and thermodynamical modulations on future changes of landfalling atmospheric rivers over western North America. Geophys. Res. Lett., 42, 7179-7186, doi:10.1002/ 2015 GL065435.

Gelman, A., and J. Hill, 2007: Data Analysis Using Regression and Multilevel/Hierarchical Models. Cambridge University Press, 648 pp.

— J. B. Carlin, H. S. Stern, D. B. Dunson, A. Vehtari, and R. B. Rubin, 2013: Bayesian Data Analysis. CRC Press, 675 pp.

Gershunov, A., and T. Barnett, 1998: ENSO influence on intraseasonal extreme rainfall and temperature frequencies in the contiguous United States: Observations and model results. J. Climate, 11, 1575-1586, doi:10.1175/1520-0442(1998)011<1575: EIOIER $>2.0 . \mathrm{CO}$; .

— and D. Cayan, 2003: Heavy daily precipitation frequency over the contiguous United States: Sources of climatic variability and seasonal predictability. J. Climate, 16, 2752-2765, doi:10.1175/1520-0442(2003)016<2752:HDPFOT >2.0.CO;2.

Guirguis, J., and R. Avissar, 2008: An analysis of precipitation variability, persistence, and observational data uncertainty in the western United States. J. Hydrometeor., 9, 843-865, doi:10.1175/2008JHM972.1.

Hanak, E., and J. R. Lund, 2012: Adapting California's water management to climate change. Climatic Change, 111, 17-44, doi:10.1007/s10584-011-0241-3.

Janowiak, J., A. Gruber, C. R. Kondragunta, R. E. Livezey, and G. J. Huffman, 1998: A comparison of the NCEP-NCAR reanalysis precipitation and the GPCP rain gauge-satellite combined dataset with observational error considerations. J. Climate, 11, 2960-2979, doi:10.1175/1520-0442(1998)011<2960: ACOTNN $>2.0 . \mathrm{CO} ; 2$.

Kalnay, E., and Coauthors, 1996: The NCEP/NCAR 40-Year Reanalysis Project. Bull. Amer. Meteor. Soc., 77, 437-471, doi:10.1175/1520-0477(1996)077<0437:TNYRP>2.0.CO;2.

Kaplan, A., M. Cane, Y. Kushnir, A. Clement, M. Blumenthal, and B. Rajagopalan, 1998: Analyses of global sea surface temperature, 1856-1991. J. Geophys. Res., 103, 18567-18589, doi:10.1029/97JC01736.

Kharin, V. V., F. W. Zwiers, X. Zhang, and G. Hegerl, 2007: Changes in temperature and precipitation extremes in the IPCC ensemble of global coupled model simulations. J. Climate, 20, 1419-1444, doi:10.1175/JCLI4066.1.

,,$-- \ldots$, and M. Wehne, 2013: Changes in temperature and precipitation extremes in the CMIP5 ensemble. Climatic Change, 119, 345-357, doi:10.1007/s10584-013-0705-8.

Mantua, N. H., S. R. Hare, Y. Zhang, J. M. Wallace, and R. C. Francis, 1997: A Pacific interdecadal climate oscillation with impacts on salmon production. Bull. Amer. Meteor. Soc., 78, 1069-1079, doi:10.1175/1520-0477(1997)078<1069: APICOW $>2.0 . \mathrm{CO} ; 2$.

Meehl, G., and Coauthors, 2014: Decadal climate prediction: An update from the trenches. Bull. Amer. Meteor. Soc., 95, 243267, doi:10.1175/BAMS-D-12-00241-1.

Peel, M. C., T. A. McMahon, and B. L. Finlayson, 2002: Variability of annual precipitation and its relationship to the El NiñoSouthern Oscillation. J. Climate, 15, 545-551, doi:10.1175/ 1520-0442(2002)015<0545:VOAPAI >2.0.CO;2.

Philander, S. G. H., 1983: El Niño Southern Oscillation phenomena. Nature, 302, 295-301, doi:10.1038/302295a0.

, 1990: El Niño, La Niña, and the Southern Oscillation. Academic Press, 289 pp.

Polade, S. D., A. Gershunov, D. R. Cayan, M. D. Dettinger, and D. W. Pierce, 2013: Natural climate variability and teleconnections to precipitation over the Pacific-North American 
region in CMIP3 and CMIP5 models. Geophys. Res. Lett., 40 , 2296-2301, doi:10.1002/grl.50491.

Ropelewski, C. F., and M. S. Halpert, 1986: North American precipitation and temperature patterns associated with the El Niño/Southern Oscillation (ENSO). Mon. Wea. Rev., 114, 2352-2362, doi:10.1175/1520-0493(1986)114<2352: NAPATP $>2.0 . C O ; 2$.

, and — 1987: Global and regional scale precipitation patterns associated with the El Niño/Southern Oscillation. Mon. Wea. Rev., 115, 1606-1626, doi:10.1175/1520-0493(1987)115<1606: GARSPP $>2.0 . \mathrm{CO} ; 2$.

—, and ——, 1996: Quantifying Southern Oscillationprecipitation relationship. J. Climate, 9, 1043-1059, doi:10.1175/ 1520-0442(1996)009<1043:QSOPR>2.0.CO;2.

Rosenzweig, C., and Coauthors, 2014: Enhancing climate resilience at NASA centers: A collaboration between science and stewardship. Bull. Amer. Meteor. Soc., 95, 1351-1363, doi:10.1175/ BAMS-D-12-00169.1.

Saha, S., and Coauthors, 2014: The NCEP Climate Forecast System version 2. J. Climate, 27, 2185-2208, doi:10.1175/ JCLI-D-12-00823.1.

Schubert, S. D., Y. Chang, M. J. Suarez, and P. J. Pegion, 2008: ENSO and wintertime extreme precipitation events over the contiguous United States. J. Climate, 21, 22-39, doi:10.1175/ 2007JCLI1705.1.

Schwing, F. B., T. Murphree, and P. M. Green, 2002: The Northern Oscillation index (NOI): A new climate index for the northeast Pacific. Prog. Oceanogr., 53, 115-139, doi:10.1016/ S0079-6611(02)00027-7.

Shabbar, A., B. Bonsal, and M. Khandekar, 1997: Canadian precipitation patterns associated with the Southern Oscillation. J. Climate, 10, 3016-3027, doi:10.1175/1520-0442(1997)010<3016: CPPAWT $>2.0 . \mathrm{CO} ; 2$.

Shang, H., J. Yan, and Z. Zhang, 2011: El Niño-Southern Oscillation influence on winter maximum daily precipitation in California in a spatial model. Water Resour. Res., 47, W11507, doi:10.1029/2011WR010415.

Stevenson, S., A. Timmermann, Y. Chikamoto, S. Langford, and P. DiNezio, 2015: Stochastically generated North American megadroughts. J. Climate, 28, 1865-1880, doi:10.1175/ JCLI-D-13-00689.1.

Swain, D. L., M. Tsiang, M. Haugen, D. Singh, A. Charland, B. Rajaratnam, and N. S. Diffenbaugh, 2014: The extraordinary California drought of 2013/2014: Character, context, and the role of climate change [in "Explaining Extreme Events of 2013"]. Bull. Amer. Meteor. Soc., 95 (7), S3-S7.

Trenberth, K., 1999: Conceptual framework for changes of extremes of the hydrological cycle with climate change. Climatic Change, 42, 327-339, doi:10.1023/A:1005488920935.
Wallace, J. M., and D. S. Gutzler, 1981: Teleconnections in the geopotential height field during the Northern Hemisphere winter. Mon. Wea. Rev., 109, 784-812, doi:10.1175/ 1520-0493(1981)109<0784:TITGHF>2.0.CO;2.

Wang, J., and X. Zhang, 2008: Downscaling and projection of winter extreme daily precipitation over North America. J. Climate, 21, 923-937, doi:10.1175/2007JCLI1671.1.

Wang, S.-Y., L. Hipps, R. R. Gillies, and J.-H. Yoon, 2014: Probable causes of the abnormal ridge accompanying the 20132014 California drought: ENSO precursor and anthropogenic warming footprint. Geophys. Res. Lett., 41, 3220-3226, doi:10.1002/2014GL059748.

_ - W.-R. Huang, and J.-H. Yoon, 2015: The North American winter 'dipole' and extremes activity: A CMIP5 assessment. Atmos. Sci. Lett., 16, 338-345, doi:10.1002/as12.565.

Wilks, D., 2011: Statistical Methods in the Atmospheric Sciences. 3rd ed. Elsevier, 704 pp.

Williams, A. P., R. Seager, J. T. Abatzoglou, B. I. Cook, J. E. Smerdon, and E. R. Cook, 2015: Contribution of anthropogenic warming to California drought during 20122014. Geophys. Res. Lett., 42, 6819-6828, doi:10.1002/ 2015 GL064924.

Willis, A. D., J. R. Lund, E. S. Townsley, and B. A. Faber, 2011: Climate change and flood operations in the Sacramento Basin, California. San Francisco Estuary Watershed Sci., 9 (2), 1-18, doi:10.15447/sfews.2014v9iss2art3.

Wolter, K., and M. S. Timlin, 1998: Measuring the strength of ENSO events: How does 1997/98 rank? Weather, 53, 315-324, doi:10.1002/j.1477-8696.1998.tb06408.x.

Yoon, J.-H., S.-Y. Wang, R. R. Gillies, B. Kravitz, L. Hipps, and P. J. Rasch, 2015: Increasing water cycle extremes in California and in relation to ENSO cycle under global warming. Nature Commun., 6, 8657, doi:10.1038/ncomms9657.

Zhang, U., J. M. Wallace, and D. S. Battisti, 1997: ENSO-like interdecadal variability: 1900-93. J. Climate, 10, 1004-1020, doi:10.1175/1520-0442(1997)010<1004:ELIV>2.0.CO;2.

Zhang, X., J. Wang, F. W. Zwiers, and P. Y. Groisman, 2010: The influence of large-scale climate variability on winter maximum daily precipitation over North America. J. Climate, 23, 29022915, doi:10.1175/2010JCLI3249.1.

Zorita, E., and H. von Storch, 1999: The analog method as a simple statistical downscaling technique: Comparison with more complicated methods. J. Climate, 12, 2474-2489, doi:10.1175/ 1520-0442(1999)012<2474:TAMAAS $>2.0 . C O ; 2$.

— J. P. Hughes, D. P. Lettenmaier, and H. von Storch, 1995: Stochastic characterization of regional circulation patterns for climate model diagnosis and estimation of local precipitation. J. Climate, 8, 1023-1042, doi:10.1175/1520-0442(1995)008<1023: SCORCP $>2.0 . \mathrm{CO} ; 2$. 